\title{
Thoracic impedance measures tissue characteristics in the vicinity of the electrodes, not intervening lung water: implications for heart failure monitoring
}

\author{
Christopher J. Charles $\cdot$ Miriam T. Rademaker • \\ Iain C. Melton • Dan Gutfinger · Neal L. Eigler • \\ Fujian Qu $\cdot$ Richard W. Troughton
}

Received: 18 August 2013/ Accepted: 5 March 2014/Published online: 12 March 2014

(C) The Author(s) 2014. This article is published with open access at Springerlink.com

\begin{abstract}
The rationale for intrathoracic impedance (Z) detection of worsening heart failure (HF) presupposes that changes in $\mathrm{Z}$ reflect changes in pulmonary congestion, but is confounded by poor specificity in clinical trials. We therefore tested the hypothesis that $\mathrm{Z}$ is primarily affected by tissue/water content in proximity to electrodes rather than by lung water distribution between electrodes through the use of a new computational model for deriving the near-field impedance contributions from the various electrodes. Six sheep were implanted with a left atrial pressure (LAP) monitor and a cardiac resynchronization therapy device which measured $\mathrm{Z}$ from six vectors comprising of five electrodes. The vector-based $\mathrm{Z}$ was modelled as the summation of the near-field impedances of the two electrodes forming the vector. During volume expansion an acute increase in LAP resulted in simultaneous reductions in the near-field impedances of the intra-cardiac electrodes, while the subcutaneous electrode showed several hours of lag (all $p<0.001$ ). In contrast, during the simulated formation of device-pocket edema (induced by fluid injection) the near-field impedance of the subcutaneous electrode had an instantaneous response, while the intra-cardiac electrodes had a minimal inconsistent response. This study
\end{abstract}

C. J. Charles $(\bowtie) \cdot$ M. T. Rademaker · I. C. Melton ·

R. W. Troughton

Christchurch Heart Institute, University of Otago,

P.O. Box 4345, Christchurch, New Zealand

e-mail: chris.charles@otago.ac.nz

D. Gutfinger - N. L. Eigler · F. Qu

Implantable Electronic Systems Division, St. Jude Medical,

Sylmar, CA, USA

N. L. Eigler

Division of Cardiology, Cedars-Sinai Medical Center, UCLA

School of Medicine, Los Angeles, CA, USA suggests that the primary contribution to the vector based $\mathrm{Z}$ is from the tissue/water in proximity to the individual electrodes. This novel finding may help explain the limited utility of $\mathrm{Z}$ for detecting worsening HF.

Keywords Implantable monitors · Hemodynamics · Left atrial pressure

\section{Introduction}

Despite treatment advances and more intensive clinical monitoring, heart failure (HF) remains one of the most common causes for hospitalization and is associated with high morbidity, mortality and economic costs [1]. The increasing use of implantable cardioverter defibrillators (ICD) and cardiac resynchronization therapy (CRT) devices in patients with HF makes it possible to remotely monitor intrathoracic impedance $(Z)$ in combination with other physiological parameters [2]. Z measurements using the right ventricular (RV) shocking coil to the device case vector $\left(\mathrm{RV}_{\text {coil }}-\mathrm{Case}\right)$ are traditionally thought to represent the resistance to electrical flow across a field extending through the lungs, such that changes in $\mathrm{Z}$ can be interpreted to reflect changes in thoracic fluid volume and pulmonary congestion [3, 4]. Based on this premise several studies have shown that it is possible to use $\mathrm{Z}$ to predict and potentially reduce hospitalizations for acute decompensated HF (ADHF) [5, 6]. However, because of the limited specificity and sensitivity of $\mathrm{Z}$ monitoring when using the $\mathrm{RV}_{\text {coil }}$-Case vector [5, 7], more recent studies have explored the use of alternative and combination vectors from CRT leads [8-10].

Pre-clinical studies using multiple vectors have shown that each vector changes at a different rate and magnitude 
in response to the development of pacing-induced $\mathrm{HF}$ [9, 10]. The left ventricular (LV) ring electrode to device case vector $\left(\mathrm{LV}_{\text {ring-Case}}\right.$ ) demonstrated the fastest rate and greatest magnitude of change, and correlated well with left atrial pressure (LAP). A recent clinical study reported that a combination of $Z$ vectors, rather than $Z$ from a single vector can successfully identify increases in thoracic fluid volume that will culminate in ADHF. Using a combination vector from either CRT or ICD leads showed improved sensitivity and a lower false positive rate compared with the single $\mathrm{RV}_{\text {coil }}$-Case vector [11].

In order to more effectively exploit the availability of $\mathrm{Z}$ from multiple vectors, we sought to gain better insight into what is being measured by these vectors. The electric current flowing between two electrodes forming a vector does not necessarily travel along a straight line across the lungs, but more likely along pathways of lesser resistance. We, therefore, hypothesized that the most significant contribution to the measured $\mathrm{Z}$ is from the electrode-tissue interface where there is high impedance to electrical flow, and that beyond this interface the contribution to the measured $\mathrm{Z}$ is negligible [12]. This is because beyond the electrode-tissue interface the current finds its way to flow through low resistance structures, such as blood vessels, that do not have a significant contribution to the measured $\mathrm{Z}$. If $\mathrm{Z}$ primarily depends on the electrode-tissue interface, then it provides a measure of the local tissue characteristics surrounding the two electrodes rather than the characteristics of tissues located farther away between the electrodes. This new interpretation may help explain why recent clinical trials have shown that monitoring of $\mathrm{Z}$ has limited effectiveness in detecting $\operatorname{ADHF}[13,14]$, particularly in the early months post-device implant when there are significant non-HF related changes occurring at the electrode-tissue interface. To test the hypothesis that $\mathrm{Z}$ primarily reflects local tissue characteristics we evaluated a new computational model for deriving the near-field impedance contributions from the various electrodes and conducted a pre-clinical experiment to illustrate how nearfield impedances may be monitored at multiple sites.

\section{Methods}

The study protocol was approved by the Animal Ethics Committee of the University of Otago, Christchurch, New Zealand.

\subsection{Implantation Procedure and Devices}

Under general anesthesia (induced by $15 \mathrm{mg} / \mathrm{kg}$ thiopentone; maintained by halothane/nitrous oxide inhalation) six sheep were implanted via the right jugular vein with an
LAP monitor (HeartPOD ${ }^{\mathrm{TM}}$ ISL) and three standard transvenous bipolar pacing/defibrillation leads with the tip electrodes fixed in the right atrial (RA) appendage, RV apex and LV epicardial region via the coronary sinus. The leads were attached to a CRT device (Promote ${ }^{\mathrm{TM}} \mathrm{RF}$ ) that was implanted subcutaneously over the left chest wall. The CRT device provided $\mathrm{Z}$ measurements along six vectors: $\mathrm{V} 1=\mathrm{LV}_{\text {ring }}$-Case; $\quad \mathrm{V} 2=\mathrm{RV}_{\text {ring }}$-Case; $\quad \mathrm{V} 3=\mathrm{RA}_{\text {ring }}{ }^{-}$ Case; $\quad \mathrm{V} 4=\mathrm{RV}_{\text {coil }}$-Case; $\quad \mathrm{V} 5=\mathrm{LV}_{\text {ring }}-\mathrm{RV}_{\text {ring }} ; \quad$ and $\mathrm{V} 6=\mathrm{LV}_{\text {ring }}-\mathrm{RA}_{\text {ring }}[9,10]$. The LAP monitor was implanted into the left atrium via a trans-septal catheterization, and provided direct LAP waveform measurements via telemetry communication $[15,16]$. All implanted devices were manufactured by St Jude Medical, Implantable Electronic Systems Division in Sylmar, CA, USA. Post-operatively, animals recovered for a minimum of 5 weeks to allow the $\mathrm{Z}$ measurements to stabilize.

\subsection{Acute study protocols}

Following the stabilization period, sheep were studied on separate days as follows:

\subsubsection{Intravascular volume expansion in normal sheep (pre-pacing)}

Sheep received a 4-h intravenous (IV) infusion of Dextran (initial dose $15 \mathrm{ml} / \mathrm{kg}$ over $30 \mathrm{~min}$, then titrated to maintain LAP at approximately $15 \mathrm{mmHg}$ above baseline values).

\subsubsection{Induction of Congestive $\mathrm{HF}$}

Sheep underwent 7 days of rapid RV pacing at $190 \mathrm{bpm}$ to induce a state of moderate stable congestive HF. This rate of RV pacing consistently raised LAP levels in this animal model by approximately $10 \mathrm{mmHg}$ [17].

\subsubsection{Intravascular volume expansion during congestive $H F$}

Sheep received a 4-h IV infusion of Dextran (as above) in the HF state. Dextran was titrated to raise LAP by approximately $15 \mathrm{mmHg}$ (from $\mathrm{HF}$ baseline levels of $16-17 \mathrm{mmHg}$ to approximately $31-32 \mathrm{mmHg}$ ).

\subsubsection{Device pocket edema}

To simulate the formation of edema within the device pocket $250 \mathrm{~mL}$ of $0.9 \%$ saline was rapidly injected via an angiocath catheter into the subcutaneous pocket containing the CRT device case. An additional $250 \mathrm{~mL}$ saline bolus was injected in 5/6 sheep $2 \mathrm{~h}$ later. 


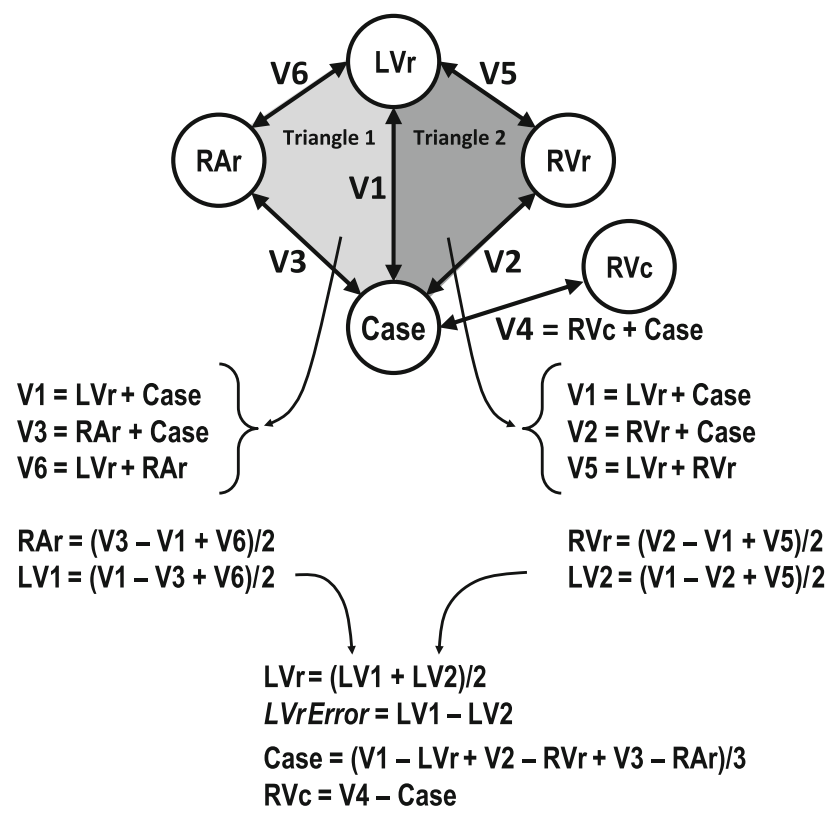

Fig. 1 Methodology for calculating near-field impedance by solving the algebraic equations of the vector-based (V1-V6) impedance measurements

\subsection{Data Acquisition and Processing}

LAP measurements were recorded every 5 min throughout the acute study protocols as previously described $[15$, 16]. Z measurements were automatically collected through the CRT device along all six vectors (V1 through V6) at $7.5 \mathrm{~min}$ intervals throughout the acute study protocols. Using equivalent circuit equations [18], the measured $\mathrm{Z}$ along each vector was modelled as the sum of the near-field contributions from the two measuring electrodes to produce a set of six linear equations (Fig. 1). The set of equations was solved algebraically to determine the near-field impedance contribution (denoted by $Z_{E}$ or the electrode name) associated with each of the five electrodes. As outlined in Fig. 1, the $Z_{E}$ associated with the $L V_{\text {ring }}$ electrode was computed using the equations corresponding to two different impedance triangles to yield LV1 and LV2 which were then averaged. The difference between LV1 and LV2 determined the measurement error associated with the computational model.

\subsection{Statistics}

All results are expressed as mean \pm SEM unless otherwise specified. For each acute study the effect on LAP, $\mathrm{Z}$ and $\mathrm{Z}_{\mathrm{E}}$ parameters were assessed using one-way repeated measures analysis of variance (ANOVA). A value of $p<0.05$ was considered statistically significant.

\section{Results}

\subsection{Near-field impedance measurement validation}

Near-field impedances $\left(Z_{E}\right)$ and the relative contributions from each of the five electrodes toward the vector-based $\mathrm{Z}$ measurements are summarized in Table 1. As expected, the highest $Z_{E}$ was associated with the smaller sized electrodes $\left(\mathrm{LV}_{\text {ring }}, \mathrm{RV}_{\text {ring }}\right.$ and $\mathrm{RA}_{\text {ring }}$ ), while the lowest $\mathrm{Z}_{\mathrm{E}}$ was associated with the larger sized electrodes (Case and $\left.\mathrm{RV}_{\text {coil }}\right)$. Electrode size also influenced the relative contributions from each of the electrodes towards the measured $\mathrm{Z}$. For a vector between any ring electrode $\left(\mathrm{LV}_{\text {ring }}, \mathrm{RV}_{\text {ring }}\right.$, and $\mathrm{RA}_{\text {ring }}$ ) and the Case electrode (V1 through V3), most of the contribution to $\mathrm{Z}$ was found to be from the ring electrode (77-87\%), while only $13-23 \%$ of the contribution was from the Case. In contrast, for the $\mathrm{RV}_{\text {coil }}$ to Case vector (V4) most of the contribution to $\mathrm{Z}$ was found to be from the subcutaneous Case electrode $(69 \%)$, with only $31 \%$ from the intra-cardiac $\mathrm{RV}_{\text {coil }}$ electrode. For the intracardiac vectors that are between two ring electrodes (V5 and V6) the contributions from the two electrodes was found to be similar. Thus, it appears that for a vector with different electrode sizes, the smaller electrode or the electrode that is surrounded by more scar tissue will be the one that is most influencing any changes in the vectorbased $\mathrm{Z}$ measurement.

The error in computing the near-field impedance for the $\mathrm{LV}_{\text {ring }}$ electrode (Fig. 1) was found to be extremely small at $2.9 \pm 3.8 \Omega(\sim 1 \%)$. This small error in combination with the observations regarding electrode size influencing $\mathrm{Z}_{\mathrm{E}}$ both validate the computational model used for deriving the near-field impedance contributions to the vector-based $\mathrm{Z}$ measurements.

\subsection{Intravascular volume expansion in normal sheep (pre-pacing)}

The total volume of Dextran administered over the $4 \mathrm{~h}$ infusion period ranged between 3,500 and $4,500 \mathrm{~mL}$. LAP increased from $7 \pm 1$ to $21 \pm 1.4 \mathrm{mmHg}$ by $30 \mathrm{~min}$ and remained stable while Dextran was being infused (Fig. 2). Once the infusion terminated, LAP gradually fell over $60 \mathrm{~min}$, but remained $2-3 \mathrm{mmHg}$ above baseline levels for the remainder of the recording period. In comparison, after a brief delay $(30 \mathrm{~min}), \mathrm{LV}_{\text {ring }}$-Case $\mathrm{Z}$ fell $(p<0.001)$, reaching a nadir at $285 \mathrm{~min}$ and remaining low. $Z_{\mathrm{E}}$ from $\operatorname{LV}_{\text {ring }}(p<0.001)$ showed a similar response, achieving a nadir after 270 min. $\mathrm{RV}_{\text {ring }}$-Case $\mathrm{Z}$ fell without delay reaching a nadir at $265 \mathrm{~min}(p<0.001)$. In contrast, $\mathrm{RV}_{\text {coil }}-$ Case $\mathrm{Z}$ demonstrated a delayed fall $(90 \mathrm{~min})$, and did not reach nadir till $375 \min (p<0.001)$. The $\mathrm{RV}_{\text {ring }}$, $\mathrm{RV}_{\text {coil }}$ and $\mathrm{RA}_{\text {ring }} \mathrm{Z}_{\mathrm{E}}$ all fell immediately and abruptly (all 
Table 1 Mean impedance measurements with relative contribution of near-field $\mathrm{Z}_{\mathrm{E}}$ to vector-based $Z$. Data averaged across all sheep $(\mathrm{N}=6)$ for all measurements over entire duration of implants $[100 \pm 22$ (SD) days]

\begin{tabular}{lclllc}
\hline Vector & Mean $\pm \mathrm{SDZ}(\Omega)$ & $\begin{array}{l}\text { Contribution } \\
\text { from 1st } \\
\text { electrode }\end{array}$ & $\begin{array}{l}\text { Contribution } \\
\text { from 2nd } \\
\text { electrode }\end{array}$ & Electrode & $\begin{array}{l}\text { Mean } \pm \mathrm{SD} \\
\mathrm{Z}_{\mathrm{E}}(\Omega)\end{array}$ \\
\hline $\mathrm{V} 1: \mathrm{LV}_{\text {ring }}$-Case & $306 \pm 53$ & $87 \% \mathrm{LV}_{\text {ring }}$ & $13 \%$ Case & $\mathrm{LV}_{\text {ring }}$ & $266 \pm 50$ \\
V2: $\mathrm{RV}_{\text {ring }}$-Case & $177 \pm 29$ & $77 \% \mathrm{RV}_{\text {ring }}$ & $23 \%$ Case & $\mathrm{RV}_{\text {ring }}$ & $137 \pm 26$ \\
V3: $\mathrm{RA}_{\text {ring }}$-Case & $254 \pm 28$ & $84 \% \mathrm{RA}_{\text {ring }}$ & $16 \%$ Case & $\mathrm{RA}_{\text {ring }}$ & $214 \pm 26$ \\
V4: $\mathrm{RV}_{\text {coil-Case }}$ & $58 \pm 6$ & $31 \% \mathrm{RV}_{\text {coil }}$ & $69 \%$ Case & Case & $40 \pm 5$ \\
V5: $\mathrm{LV}_{\text {ring }}-\mathrm{RV}_{\text {ring }}$ & $403 \pm 50$ & $66 \% \mathrm{LV}_{\text {ring }}$ & $34 \% \mathrm{RV}_{\text {ring }}$ & $\mathrm{RV}_{\text {coil }}$ & $18 \pm 5$ \\
V6: $\mathrm{LV}_{\text {ring }}-\mathrm{RA}_{\text {ring }}$ & $480 \pm 58$ & $55 \% \mathrm{LV}_{\text {ring }}$ & $45 \% \mathrm{RA}_{\text {ring }}$ & & \\
& & & & $\mathrm{LV} 1$ & $268 \pm 50$ \\
& & & & $\mathrm{LV} 2$ & $265 \pm 50$ \\
\hline
\end{tabular}

$p<0.001)$ mirroring the acute change in LAP, and reaching nadirs at 45, 30 and $30 \mathrm{~min}$, respectively. Despite the observation that LAP fell within $60 \mathrm{~min}$ following Dextran infusion, the intra-cardiac $Z_{\mathrm{E}}$ measurements remained suppressed for the duration of the recording period. Case $\mathrm{Z}_{\mathrm{E}}$ changes were less consistent, with the level actually rising initially and ultimately reducing with significant lag.

\subsection{Induction of congestive $\mathrm{HF}$}

Pacing at $190 \mathrm{bpm}$ induced a moderate state of $\mathrm{HF}$ as indicated by rapid and significant increases in LAP, rising from a pre-pacing baseline of $7 \pm 1-16 \pm 1 \mathrm{mmHg}$ within a few hours of pacing, before plateauing $(p<0.001)$. Pacing induced the expected decreases in vector-based $\mathrm{Z}$, falling from pre-pacing levels of $310 \pm 21-257 \pm 21 \Omega$, $186 \pm 12-162 \pm 10 \Omega$ and $61 \pm 1-54 \pm 2 \Omega$ for $L V_{\text {ring }}{ }^{-}$ Case, $\mathrm{RV}_{\text {ring }}$-Case and $\mathrm{RV}_{\text {coil }}$-Case, respectively (all $p<0.001)$. Similarly, pacing produced falls in the $\mathrm{Z}_{\mathrm{E}}$ for $\mathrm{LV}_{\text {ring }} \quad(269 \pm 19-220 \pm 19 \Omega, \quad \mathrm{p}<0.001), \quad \mathrm{RV}_{\text {ring }}$ $(145 \pm 12-125 \pm 19 \Omega, p=0.004)$ and Case $(41 \pm 2.1$ vs. $37 \pm 1.9 \Omega, p=0.014)$ electrodes. The $\mathrm{Z}_{\mathrm{E}}$ of the $\mathrm{RV}_{\text {coil }}(20.2 \pm 2.1-17.5 \pm 2.1 \Omega, p=0.07)$ and $\mathrm{RA}_{\text {ring }}$ $(215 \pm 11-203 \pm 11 \Omega, p=0.16)$ electrodes also tended to decline.

\subsection{Intravascular volume expansion during congestive $\mathrm{HF}$}

The total volume of Dextran administered over the infusion period was 2,900-4,000 mL. Acute volume loading increased LAP from $16 \pm 1$ to $31 \pm 1.2 \mathrm{mmHg}$ by $30 \mathrm{~min}$, with pressures remaining stable for the duration of the infusion (Fig. 3). LAP gradually reduced following termination of Dextran infusion, but remained above preDextran infusion levels. Both $\mathrm{LV}_{\text {ring }}-$ Case and $\mathrm{RV}_{\text {coil }}-\mathrm{Case}$ vectors showed a small but consistent rise (both $p<0.001$ ) in response to Dextran (Fig. 3), with similar rises observed for $\mathrm{Z}_{\mathrm{E}}$ of the $\mathrm{LV}_{\text {ring }}(p<0.001)$ and Case $(p<0.001)$. In contrast, $\mathrm{RV}_{\text {ring }}-$ Case vector-based $\mathrm{Z}$ and $\mathrm{Z}_{\mathrm{E}}$ from $\mathrm{RV}_{\text {ring }}$, $\mathrm{RA}_{\text {ring }}$ and $\mathrm{RV}_{\text {coil }}$ all showed prompt and consistent falls (all $p<0.001$ ), reaching nadirs by $37.5 \mathrm{~min}$ and remaining depressed for the duration of the recording period.

\subsection{Device pocket edema}

There was a small but consistent elevation in LAP $(\sim 2 \mathrm{mmHg} ; \quad p<0.001)$ during the study day which appeared unrelated to fluid injection (Fig. 4). All three vector-based $\mathrm{Z}$ showed an immediate decline (all $p<0.001)$ in response to fluid injection into the device pocket, and remained lower than baseline. $\mathrm{Z}_{\mathrm{E}}$ from the Case showed a prompt and dramatic fall in response to pocket fluid injection $(p<0.001)$, dropping from $\sim 43$ to $\sim 30 \Omega$ following the first injection, and then to $\sim 27 \Omega$ following the second injection. In contrast, $\mathrm{Z}_{\mathrm{E}}$ associated with the other four electrodes showed minimal and inconsistent changes unrelated to fluid injection.

\section{Discussion}

In this study we demonstrate for the first time that changes in vector-based $\mathrm{Z}$ measurements may readily develop in response to changes occurring at the electrode-tissue interface, thereby providing a possible mechanism that explains why $\mathrm{Z}$ monitoring has limited sensitivity and specificity in detecting ADHF [13]. The hypothesis that $Z$ primarily reflects local tissue characteristics suggests that non-HF events, such as healing post-implant, lead migration/dislodgement, and device-pocket infection, can easily confound the interpretation of changes in $\mathrm{Z}$ measurements $[4,14]$. Thus, in the current study we evaluated changes in both vector-based $\mathrm{Z}$ and $\mathrm{Z}_{\mathrm{E}}$ responses during rapid changes in LAP induced by volume and non-volume-dependent mechanisms. Volume loading with dextran is a standard physiological model designed to acutely increase 
Fig. 2 Mean \pm SEM LAP, vector-based and near-field impedance responses to acute intravascular volume expansion in six normal sheep

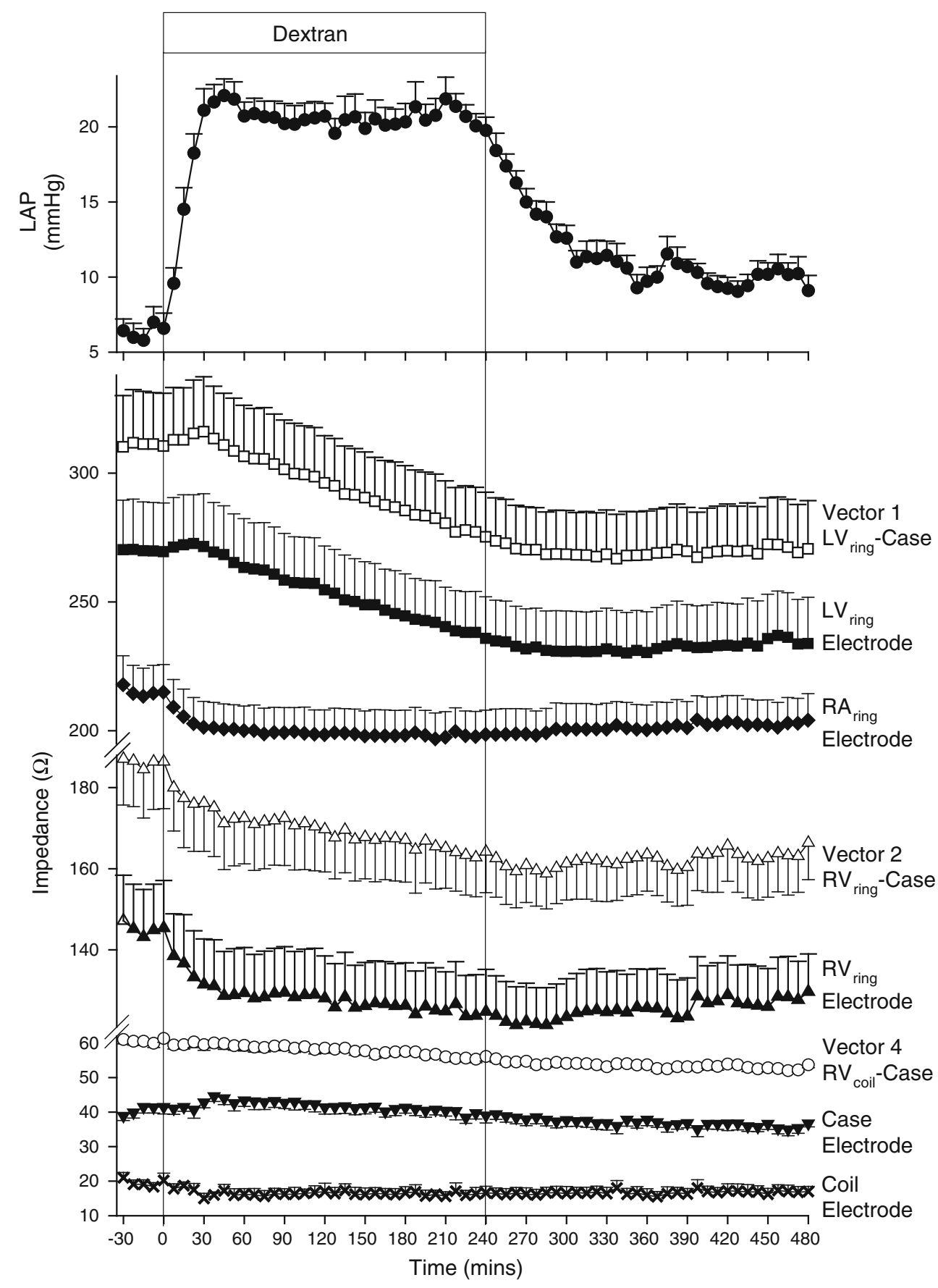

intravascular and intracardiac volumes [19, 20]. The rate and duration of dextran infusion in the current study was sufficient to increase intravascular and intracardiac volumes with an approximate $15 \mathrm{mmHg}$ rise in LAP, but is unlikely to have caused pulmonary edema. Rapid ventricular pacing is a well established animal model of congestive HF which consistently induces significant sodium and water retention, changes in intracardiac volumes and pressures and pulmonary edema [17]. This model has been previously used in our lab to study vector-based impedance changes with the onset and offset of congestive HF, thereby modelling ADHF decompensation and recovery [10]. Results from the current study confirm that pacing induced HF not only reduces all vector-based impedances, as previously shown [10], but also consistently reduces $Z_{E}$ derived from each of the electrodes.

Results from the current study support our hypothesis that $\mathrm{Z}$ primarily reflects local tissue characteristics by demonstrating that intrathoracic impedance measurements reflect the local tissue and fluid conditions surrounding each of the 
electrodes, rather than the characteristics of tissues located farther away in the region between the measuring electrodes. The highest near-field impedance $\left(\mathrm{Z}_{\mathrm{E}}\right)$ was associated with the smaller-sized $\mathrm{LV}_{\text {ring }}, \mathrm{RV}_{\text {ring }}$ and $\mathrm{RA}_{\text {ring }}$ electrodes which had greater resistance to electrical flow at the electrode-tissue interface (Table 1). The lowest $\mathrm{Z}_{\mathrm{E}}$ was associated with the Case and $\mathrm{RV}_{\text {coil }}$ electrodes, consistent with these electrodes being larger in size with less resistance to electrical flow. The $\mathrm{LV}_{\text {ring }}$ electrode had the highest $\mathrm{Z}_{\mathrm{E}}$, consistent with this electrode being surrounded by more tissue and less blood.
To construct the mathematical model we hypothesized that the current flows along a pathway from the first electrode to the second electrode which includes three components; (1) the tissues adjacent to the first electrode; (2) the tissues and/or blood located farther away between the two electrodes; and (3) the tissues adjacent to the second electrode. The measured impedance between the first electrode and the second electrode therefore can be modelled as the summation of the impedance associated with each of these pathway components. We also hypothesized
Fig. 3 Mean \pm SEM left atrial pressure (LAP), vector-based and electrode-based impedance responses to intravascular volume expansion with Dextran in six sheep with stable pacinginduced $\mathrm{HF}$

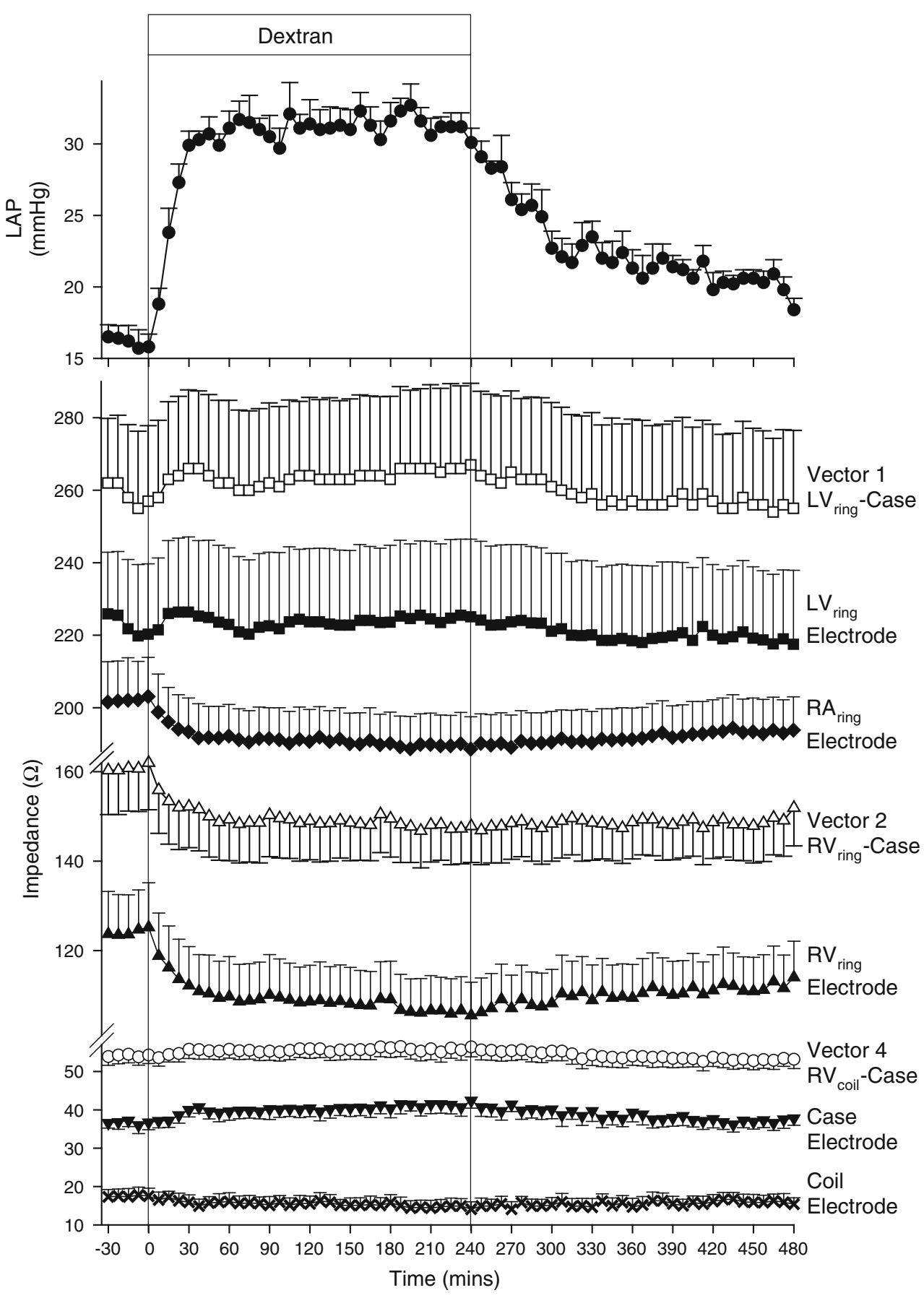


that the contribution to the measured impedance between the first and the second electrode is greatest from the 1st and 3rd components of the pathway, and that the contribution from the 2nd component is significantly lower such that it may be ignored. We believe this hypothesis to be correct because the electrical current will find its way to flow through a pathway between the electrodes that has the lowest impedance to electrical flow, such as along blood vessels. Thus, the mathematical model for the measured impedance between two electrodes was simplified to consist of only the 1 st and 3rd components. Since we had six measurements of vector based impedance from five electrodes we were able to compute the contribution from the $\mathrm{LV}_{\text {ring }}$ electrode in more than one way (LV1 and LV2) which allowed us to verify our hypothesis that the impedance associated with the 2nd component pathway can be ignored.

The most striking example of impedance reflecting the local tissue and fluid conditions surrounding an electrode was seen in the device pocket edema study where, although vector-
Fig. 4 Mean \pm SEM LAP, vector-based and near-field impedance responses to injection of fluid into the CRT$\mathrm{D}$ device pocket in six normal sheep

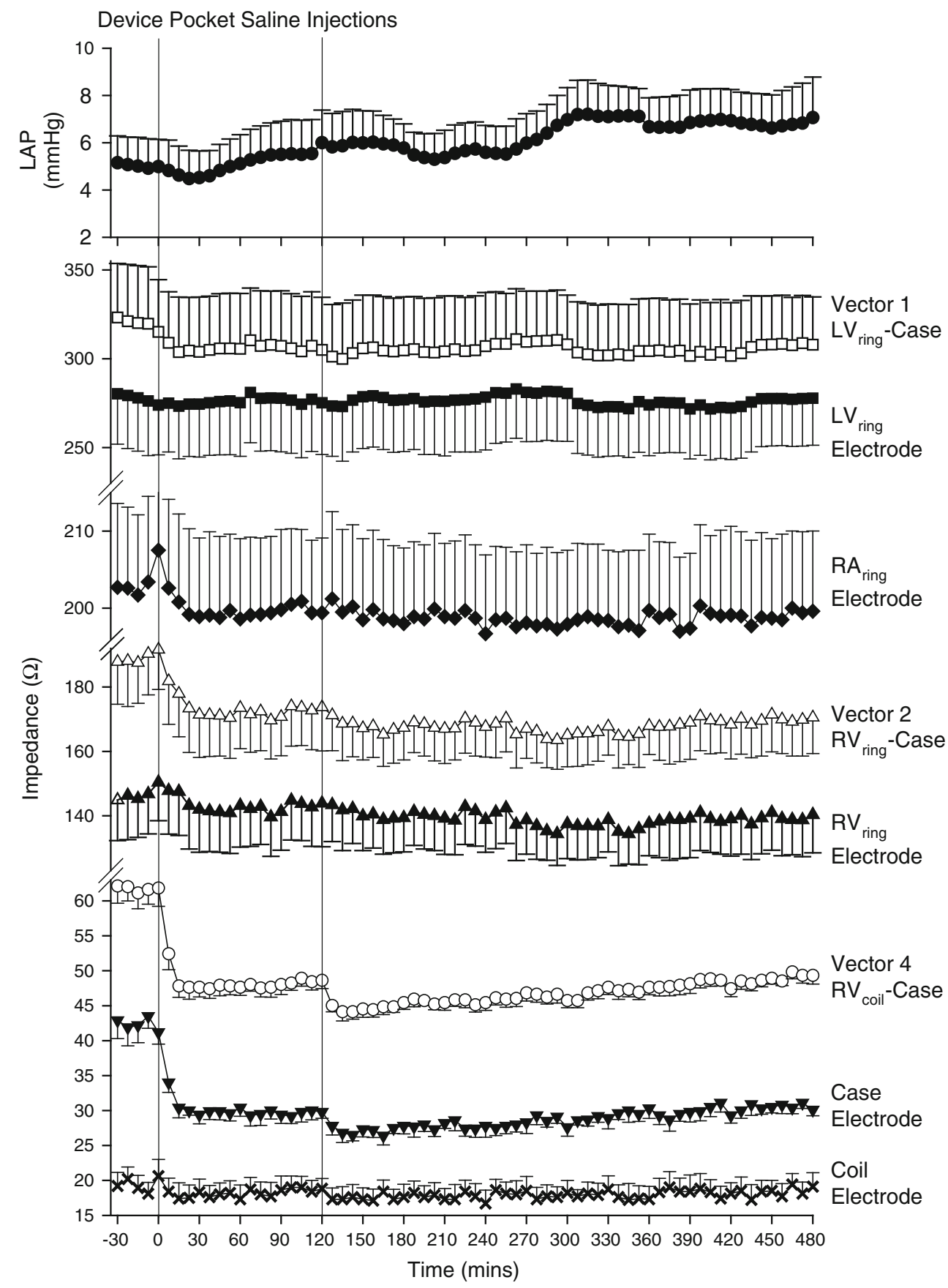


based $\mathrm{Z}(\mathrm{V} 1, \mathrm{~V} 2$, and V4) fell in response to the injection of fluid into the device pocket, near-field computation demonstrated that the marked and precipitous fall in the Case $Z_{E}$ contributed most, if not all, to the decrease in the vector-based $\mathrm{Z}$. This can be seen in Fig. 5a where the falls in Z for V1, V2, and V4 are plotted at $30 \mathrm{~min}$ following saline injection into the pocket. The reduction in Z for V1 and V4 is contributed almost exclusively by the fall in $Z_{E}$ of the Case electrode, with little if any contribution from the $Z_{E}$ of the $L V_{\text {ring }}$ or $R V_{\text {coil }}$ electrodes, respectively. The large accumulation of fluid surrounding the Case resulted in little discernable change in LAP or $\mathrm{Z}_{\mathrm{E}}$ for any of the other implanted electrodes located far away from the device pocket. A similar response pattern in the measured $\mathrm{Z}$ is classically seen whenever a pulse generator is replaced, which results in the formation of local edema within the device pocket during the first $24 \mathrm{~h}$, followed by the normal phases of tissue healing occurring over the subsequent weeks to months. Thus, device pocket edema induces significant reductions in the measured $\mathrm{Z}$ that may be falsely interpreted [4]. However, with the ability to remove the contribution of the Case electrode from the measured vector-based $Z$, it is possible to monitor impedance without it being subjected to otherwise confounding changes that are occurring within the device pocket.
Fig. 5 Relative contributions of near-field impedances to changes in vector based impedance measured in response to device pocket saline injection at $30 \mathrm{~min}(\mathbf{a})$; and intravascular volume expansion at $30 \mathrm{~min}(\mathbf{b})$ and $300 \mathrm{~min}(\mathbf{c})$

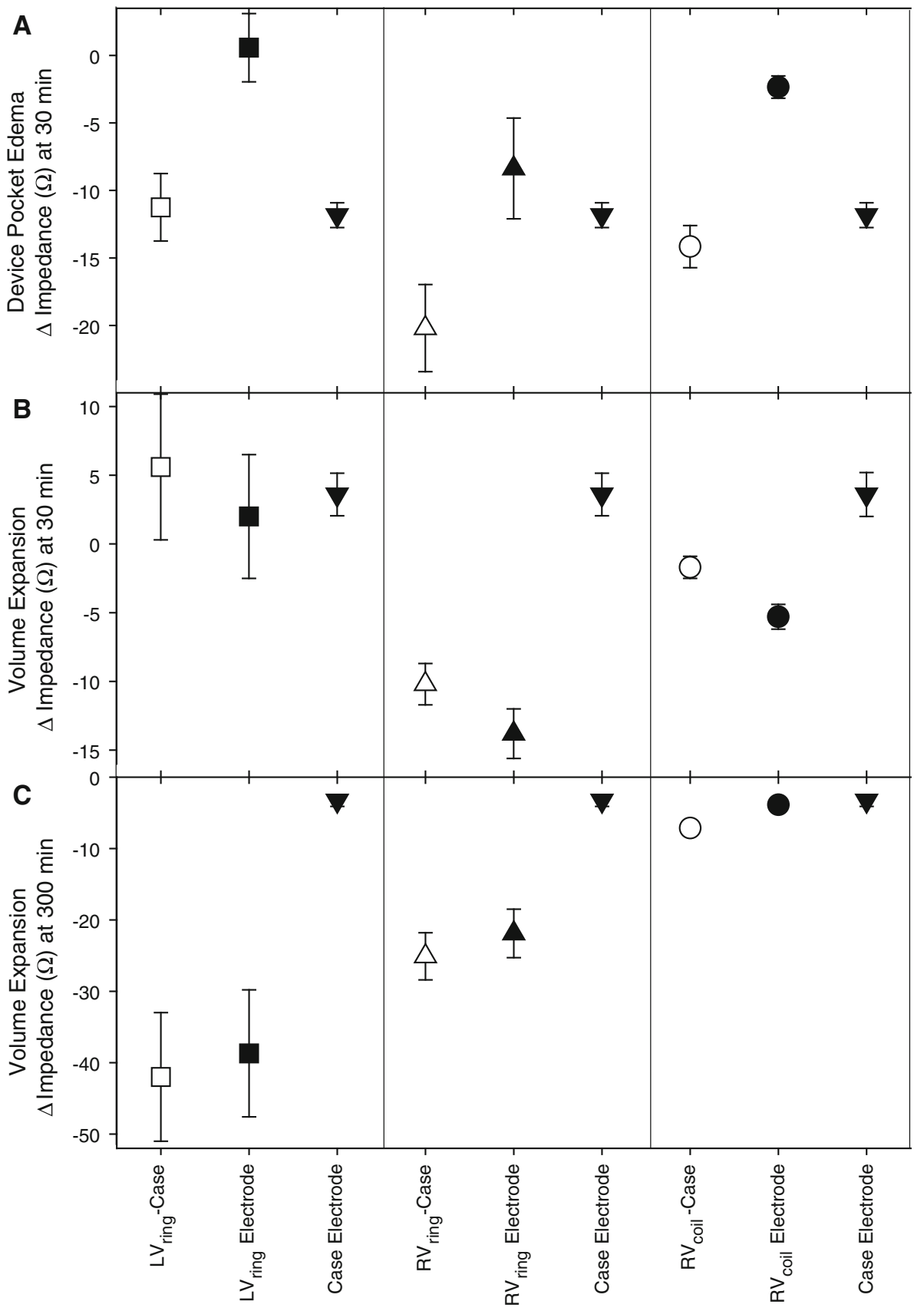


The hypothesis that $\mathrm{Z}$ primarily reflects local tissue characteristics is further supported by the intravascular volume expansion studies performed both in normal (prepacing) and HF sheep which induced a significant increase in LAP that was promptly tracked by corresponding reductions in the $Z_{E}$ measurements from the intra-cardiac $\left(\mathrm{RV}_{\text {ring }}, \mathrm{RA}_{\text {ring }}\right.$ and $\left.\mathrm{RV} \mathrm{V}_{\text {coil }}\right)$ electrodes. The acute and the delayed responses to intravascular volume expansion in the normal (pre-pacing) sheep are illustrated in Fig. 5b and c, respectively. At 30 min following commencement of volume expansion, which corresponds to the time when LAP first peaked, there is a dramatic fall in Z for V2 and V4, whereas for $\mathrm{V} 1$ there is a slight unexpected increase (Fig. 5b). Near-field computation demonstrates that the acute reduction in $\mathrm{Z}$ for $\mathrm{V} 2$ and V4 is contributed entirely by a fall in the $Z_{E}$ for the $R V_{\text {ring }}$ and $R V_{\text {coil }}$ electrodes, respectively. Because the $R V_{\text {ring }}$ and $R V_{\text {coil }}$ electrodes are located within the RV chamber, a rapid increase in chamber volume causes more fluid to surround the electrodes and less tissue to be in contact with the electrodes, such that the near-field contribution to the measured vector-based $\mathrm{Z}$ is proportionally reduced.

Following the $30 \mathrm{~min}$ time point the $\mathrm{Z}$ for $\mathrm{V} 1$ has a steady decrease (Fig. 2), which is occurring over the time period when the infused fluid is being redistributed to other compartments. At the 300 min time point (Fig. 5c) nearfield computation demonstrates that virtually all of the reduction in $\mathrm{Z}$ for $\mathrm{V} 1$ is contributed by the fall in the $\mathrm{Z}_{\mathrm{E}}$ for the $L V_{\text {ring }}$ electrode. Although the $L V_{\text {ring }}$ electrode is implanted within an epicardial blood vessel, its delayed response suggests that the $\mathrm{LV}_{\text {ring }}$ electrode is not in direct communication with the RV blood pool. This may be secondary to possible formation of scar tissue within the distal coronary venous implant site (confirmed by autopsy in some animals) causing obstruction to blood flow. Importantly, $Z_{E}$ from the $L V_{\text {ring }}$ electrode was found to be sensitive to congestion within the adjacent epicardial fat, as demonstrated post volume expansion in canine studies in our lab (unpublished observations), and to pericardial fluid volume and the degree of contact between the $\mathrm{LV}_{\text {ring }}$ electrode and the pericardial sac [21]. Thus, an increase in the degree of tissue contact between the $\mathrm{LV}_{\text {ring }}$ electrode and the pericardial sac as a consequence of an expanding cardiac chamber volume may explain the unexpected initial increase observed in response to acute volume infusion, while the later development of epicardial fat edema may explain the delayed response. A change in the degree of contact between the $L V_{\text {ring }}$ electrode and the pericardial sac may also occur in response to changes in posture or pericardial fluid volume irrespective of pulmonary congestion, and may result in false interpretations of the measured impedance as previously reported [21]. However, the influence of free flowing pericardial fluid volume and posture may be less critical in patients with a scarred pericardial space following open heart surgery, or an episode of pericarditis.

There were variations in the recovery pattern of the measured $Z_{E}$ following cessation of volume loading that depended on the electrode implant location. All five electrodes had a much slower recovery rate in $\mathrm{Z}_{\mathrm{E}}(>12 \mathrm{~h})$ compared to LAP $(\sim 3 \mathrm{~h})$. The intra-cardiac right-sided electrodes demonstrated a faster recovery compared to the $L V_{\text {ring }}$ and Case electrodes. The delay in recovery of impedance in comparison to LAP is consistent with
Fig. 6 Example of vectorbased (left panel) and near-field (right panel) impedance trend plots from a canine implanted with pacing/defibrillation leads using identical methodology to that described for sheep in this study. A micro-dislodgement of the LV lead occurred on day 18

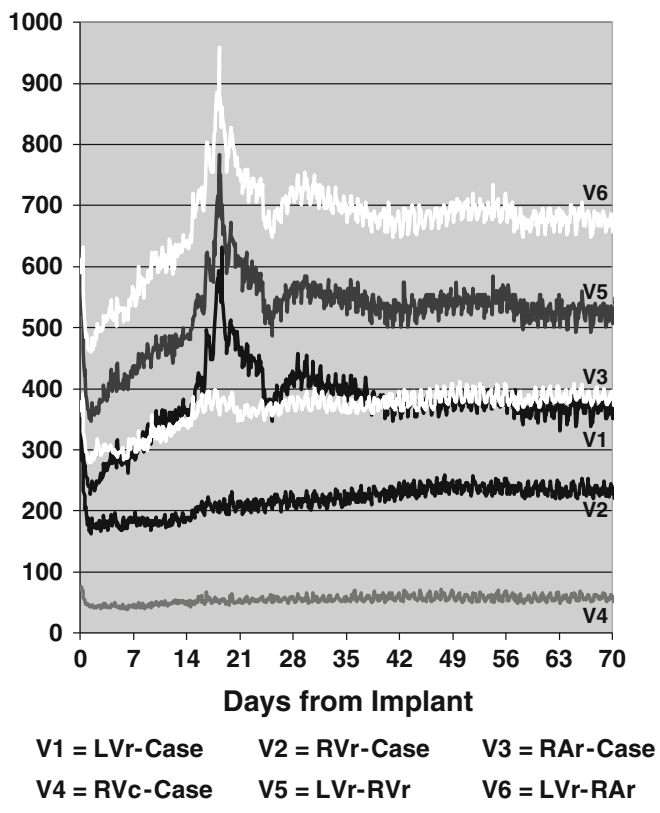


previous reported findings [10], and is likely a consequence of the longer time required to restore the local fluid volume conditions surrounding the various electrodes, particularly when located outside the intravascular space. Similarly, termination of rapid ventricular pacing caused a precipitous acute fall in LAP, followed by a gradual recovery over the subsequent $12 \mathrm{~h}$. This was in contrast to the significantly slower recovery seen in $Z_{E}(\sim 3$ days-data not shown), which is consistent with previously reported data for $Z_{V}$ [10]. The lag seen between $Z_{E}$ and LAP is likely a consequence of $Z_{E}$ being more a reflection of the local volume and corresponding tissue contact rather than pressure.

\subsection{Illustrative case studies}

1. Micro-dislodgement. Figure 6 provides an example of the $\mathrm{Z}$ measurements acquired from a canine surgically prepared in a similar manner to the sheep in this study
[9]. This animal developed a micro-dislodgement of the LV lead during the third week post-implant. The trend data demonstrates that during the first $24 \mathrm{~h}$ postimplant there is a significant decrease in the measured $\mathrm{Z}$ across all six vectors, which is consistent with the development of edema in the vicinity of all five electrodes. During the subsequent weeks the $\mathrm{Z}$ measurements gradually increased as the local edema resolved. However, there is a sudden disturbance in the measured $\mathrm{Z}$ on day 18 post-implant seen across the three vectors having the $\mathrm{LV}_{\text {ring }}$ in common $(\mathrm{V} 1, \mathrm{~V} 5$, and V6). Examination of the $Z_{E}$ shows that only the $L V_{\text {ring }}$ electrode recorded a significant increase, with no change noted in the contribution from the other four electrodes. The ability to isolate the micro-dislodgement event into a single electrode additionally supports the computational model used to derive the near-field impedance contributions.
Fig. 7 Example of near-field impedance trend plots shown from a patient with ischemic cardiomyopathy. Patient was hospitalized following an episode of persistent atrial fibrillation (AF). During hospitalization patient received both intravenous diuretic therapy and AV node ablation $(\mathrm{AVN})$
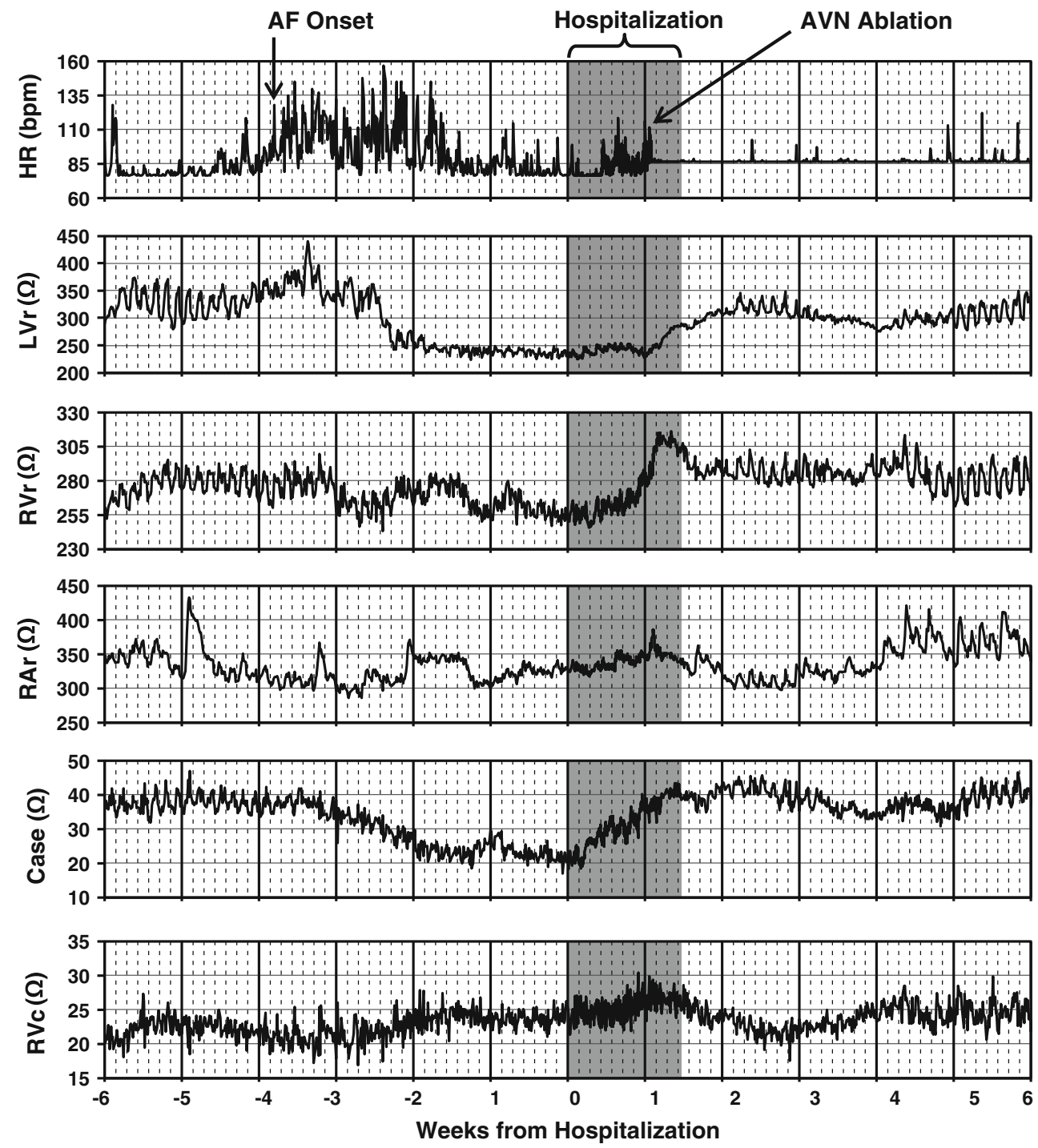
2. Hospitalization for $A D H F$. An example of $\mathrm{Z}_{\mathrm{E}}$ data acquired from a 66 year-old patient with ischemic cardiomyopathy is shown as a trend plot over time in Fig. 7. This patient provided informed consent to participate in the clinical trial reported by Binkley and colleagues [11]. Approximately 2 months following implant, the patient developed an episode of persistent atrial fibrillation that resulted in hospitalization for ADHF. During hospitalization, the patient was treated with intravenous diuretic therapy, and underwent an AV-node ablation procedure (Fig. 7). In response to this treatment, the $Z_{E}$ from the $R V_{\text {ring }}$ and Case electrodes increased dramatically, while the rise for the $\mathrm{LV}_{\text {ring }} \mathrm{Z}_{\mathrm{E}}$ was more gradual and continued posthospital discharge. Interestingly, the $Z_{E}$ from the $\mathrm{RV}_{\text {coil }}$ and $\mathrm{RA}_{\text {ring }}$ electrodes had more noise and measurement artifact, and did not coincide with the clinical course. This case illustrates that the response seen in $Z_{E}$ during the development and recovery from ADHF varies with the electrode location and the local tissue characteristics.

\section{Summary}

Taken together, the results of the present study validate the computational model used to derive the near-field impedances $\left(Z_{E}\right)$, and demonstrate that vector-based $Z$ primarily depends on the impedance from the tissues in the vicinity of the measuring electrodes, and therefore, reflects local tissue characteristics. This finding may explain why vectorbased $\mathrm{Z}$ can display changes that do not coincide with pulmonary congestion, particularly in the early months post-implant when there are significant changes occurring at the electrode-tissue interface. This is consistent with the results from a recent clinical trial which demonstrate that the positive predictive value of a $\mathrm{Z}$ monitoring algorithm is particularly low in the initial 6 months post-implant, but subsequently improves over time [13]. Instabilities postimplant are more likely to occur with $\mathrm{Z}$ that are associated with a passive fixation lead, such as an LV pacing lead, where there is a greater chance for a micro-dislodgement to occur (Fig. 6). Therefore, it may be preferable to allow more time for the electrode-tissue interface to stabilize before relying on $\mathrm{Z}$ measurements for clinical decision making, or to rely on $\mathrm{Z}$ vectors that are derived from an active fixation lead ( $\mathrm{RV}_{\text {coil }}$-Case and $\mathrm{RV}_{\text {ring-Case). Once }}$ the electrode-tissue interface is stabilized, this study demonstrates that the $\mathrm{Z}_{\mathrm{E}}$ associated with the intra-cardiac electrodes $\left(R V_{\text {ring }}, R A_{\text {ring }}\right.$, and $\left.R V_{\text {coil }}\right)$ respond faster than the $Z_{E}$ associated with the $L V_{\text {ring }}$ and Case electrode to an expanding intra-cardiac chamber volume. The $\mathrm{Z}_{\mathrm{E}}$ associated with the $L_{\text {ring }}$ and Case electrodes are additionally influenced by changes occurring within the pericardial space or device pocket, which may not coincide with pulmonary congestion. Therefore, relying on the $\mathrm{Z}_{\mathrm{E}}$ associated with the intra-cardiac electrodes for clinical decision-making may be more advantageous than other electrodes or $\mathrm{Z}$ vectors.

\section{Conclusion}

We have reported for the first time a validated method for determining the relative contributions to the measured vector-based impedance from the various electrodes, and have demonstrated that vector-based impedance measurements predominantly reflect physical phenomena occurring in the vicinity of the measuring electrodes rather than farther away within the pulmonary parenchyma. Thus, the near-field computational model offers a new paradigm for examining impedance data from multi-lead devices which may prove clinically-useful in monitoring changes at specific anatomical locations in close proximity to the individual recording electrodes. The results of this study help explain why vector-based impedance measurements may display changes that do not necessarily correlate with the presence of pulmonary congestion, and support the hypothesis that intrathoracic impedance actually measures local tissue characteristics rather than intervening lung water.

Acknowledgments We are grateful to the staff of the University of Otago, Christchurch Animal Research Area for animal care. Supported in part by a research grant from St Jude Medical, and by The Health Research Council of New Zealand.

Conflict of interest Eigler is an inventor of the HeartPOD ${ }^{\mathrm{TM}}$ device; Gutfinger, Eigler and Qu are all employees of St Jude Medical which has commercial interests in the HeartPOD ${ }^{\mathrm{TM}}$ and Promote ${ }^{\mathrm{TM}}$ devices.

Open Access This article is distributed under the terms of the Creative Commons Attribution License which permits any use, distribution, and reproduction in any medium, provided the original author(s) and the source are credited.

\section{References}

1. American Heart Association Statistics Committee and Stroke Statistics Subcommittee. Heart disease and stroke statistics-2008 update: a report from the American heart association statistics committee and stroke statistics subcommittee. Circulation. 2008; 117:e25-146.

2. Merchant FM, Dec GW, Singh JM. Implantable sensors for heart failure. Circ Arrhythm Electrophysiol. 2010;3:657-67.

3. Yu CM, Wang L, Chau E, et al. Intrathoracic impedance monitoring in patients with heart failure: correlation with fluid status and feasibility of early warning preceding hospitalization. Circulation. 2005;112:841-8. 
4. Wang L. Fundamentals of intrathoracic impedance monitoring in heart failure. Am J Cardiol. 2007;99(suppl):3G-10G.

5. Ypenburg C, Bax JJ, van der Wall EE, Schalij MJ, van Erven L. Intrathoracic Impedance monitoring to predict decompensated heart failure. Am J Cardiol. 2007;99:554-7.

6. Catanzarita D, Lunati M, Landolina M, et al. Monitoring intrathoracic impedance with an implantable defibrillator reduces hospitalizations in patients with heart failure. PACE. 2009;32:363-70.

7. Vollmann D, Nagele H, Schauerte P, et al. Clinical utility of intrathoracic impedance monitoring to alert patients with an implanted device of deteriorating chronic heart failure. Eur Heart J. 2007;28:1835-40.

8. Maines $\mathrm{M}$, Landolina $\mathrm{M}$, Lunati $\mathrm{M}$, et al. Intrathoracic and ventricular impedances are associated with changes in ventricular volume in patients receiving defibrillators for CRT. PACE. 2010;33:64-73.

9. Khoury DS, Naware M, Siou J, et al. Ambulatory monitoring of congestive heart failure by multiple bioelectric impedance vectors. J Am Coll Cardiol. 2009;53:1075-81.

10. Rademaker MT, Charles CJ, Melton IC, et al. Monitoring heart failure: comparison of left atrial pressure with intrathoracic impedance and natriuretic peptide measurements in an experimental model of ovine heart failure. Clin Sci. 2011;120:207-17.

11. Binkley PF, Porterfied JG, Porterfield LM, et al. Feasibility of using multivector impedance to monitor pulmonary congestion in heart failure patients. J Interv Card Electrophysiol. 2012;35:197-206.

12. Wittkampf FHM, Nakagawa H. RF catheter ablation: lessons on lesions. PACE. 2006;29:1285-97.

13. Conraads VM, Tavazzi L, Santini M, et al. Sensitivity and positive predictive value of implantable intrathoracic impedance monitoring as a predictor of heart failure hospitalizations: the SENSE-HF trial. Eur Heart J. 2011;32:2266-73.

14. Van Veldhuisen DJ, Braunschweig F, Conraads V, et al. Intrathoracic impedance monitoring, audible patient alerts, and outcome in patients with heart failure. Circulation. 2011;124:1719-26.

15. Ritzema J, Melton IC, Richards AM, et al. Direct left atrial pressure monitoring in ambulatory heart failure patients: initial experience with a new permanent implantable device. Circulation. 2007;116:2952-9.

16. Ritzema J, Troughton R, Melton I, et al. Physician-directed patient self-management of left atrial pressure in advance chronic heart failure. Circulation. 2010;121:1086-95.

17. Rademaker MT, Charles CJ, Espiner EA, Frampton CM, Nicholls MG, Richards AM. Natriuretic peptide responses to acute and chronic ventricular pacing in sheep. Am $\mathrm{J}$ Physiol. 1996;270:H594-602.

18. Bini GC, Paperini L, Pauletti M, Pardini E, Manfredini E, Corbucci G. A method to calculate tissue impedance through a standard bipolar pacing lead. Cardiovasc Eng. 2006;6:45-52.

19. Charles CJ, Nicholls MG, Rademaker MT, Richards AM. Adrenomedullin modulates the neurohumoral response to acute volume loading in normal conscious sheep. $\mathrm{J}$ Endocrinol. 2002;173:123-9.

20. Charles CJ, Tang F, Cameron VA, Richards AM, Espiner EA. Intracerebroventricular atrial natriuretic factor (ANF) antiserum inhibits volume-induced ANF in sheep: evidence for the brain's regulation of ANF secretion. Endocrinology. 1991;129:2225-30.

21. Nakashima T, Takasugi N, Kubota $T$, et al. 'False-positive' intrathoracic impedance monitor alarm caused by amiodaroneinduced hypothyroidism in a patient with cardiac resynchronization therapy-defibrillator. Europace. 2012;14:768-9. 